\title{
Calcium Carbonate Crystal Measurement
}

National Cancer Institute

\section{Source}

National Cancer Institute. Calcium Carbonate Crystal Measurement. NCI Thesaurus.

Code C74669.

The determination of the amount of calcium carbonate crystals present in a sample. 